\title{
Editorial
}

\section{Inverse Dynamics Problems for a Sustainable Future}

\author{
Hamed Kalhori ${ }^{1,2}$ (D)
}

1 School of Mechanical and Mechatronic Engineering, University of Technology Sydney, Sydney, NSW 2007, Australia; Hamed.Kalhori@uts.edu.au

2 Department of Mechanical Engineering, Faculty of Engineering, Bu-Ali Sina University, Hamedan 65178, Iran

Citation: Kalhori, H. Inverse Dynamics Problems for a Sustainable Future. Vibration 2021, 4, 130-132. https://doi.org/10.3390/ vibration4010011

Received: 7 February 2021

Accepted: 10 February 2021

Published: 12 February 2021

Publisher's Note: MDPI stays neutral with regard to jurisdictional claims in published maps and institutional affiliations.

Copyright: (C) 2021 by the author. Licensee MDPI, Basel, Switzerland. This article is an open access article distributed under the terms and conditions of the Creative Commons Attribution (CC BY) license (https:// creativecommons.org/licenses/by/ $4.0 /)$.
Inverse dynamics problems and associated aspects are all around us in everyday life but are commonly overlooked and/or not fully comprehended. However, they are of utmost significance when it comes to structural integrity and safety of engineering components we constantly interact with in our daily lives. The identification of dynamic characteristics and the estimation of applied loads to evaluate the structural health of aerospace structurers such as airliners, and/or on civil structures, such as large bridges with thousands of vehicles crossing daily, are tangible examples that show the fundamental importance of inverse dynamics problems. The inverse theory of network-like structures, with numerous practical applications in science and engineering, is an essential part of a swiftly growing area of applied mathematics. Such inverse problems encompass various applications in structural health monitoring, in water, electricity, gas, and traffic networks, in nano-electronics and quantum computing, in material science, and in biology [1].

But why solve problems inversely? What does that mean exactly? The estimation of system inputs or internal reactions by direct measurements is complicated or impossible for many real systems, either because the system input is inaccessible or unknown or simply because the nature of input is unknown and therefore cannot be instrumented. An inverse problem strategy is, therefore, a promising solution for such scenarios. Inverse problems are about identifying the cause of an effect, utilizing a set of observations and the measurement of the system response. As opposed to a forward problem yielding the system response, an inverse problem manipulates the effects considering the system's natural behavior to predict the inputs to the system. Figure 1 depicts a schematic of the forward and inverse problems.
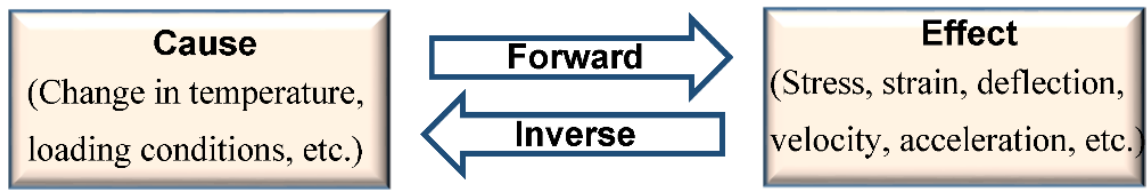

Figure 1. Forward and inverse problems.

In vibration engineering, the extraction of natural dynamic behaviors of a system, commonly referred to as an experimental modal analysis, can also be considered as an inverse problem deconvolving the input from the measured output. The modal analysis can be utilized to investigate the structural damage [2]. As a more advanced technique, operational modal analysis, OMA, seeks the system's natural behavior, manipulating the measured vibration response only [3]. Once the modal analysis is completed, it can be exploited to update the finite element model of the system to estimate the system response to more complicated loading and environmental conditions [4].

There is normally complex mathematics behind most inverse problems. Solving an inverse problem might not result in a sufficiently good outcome since the inverse problems are usually intrinsically ill-posed due to the ill-conditioned nature of the system frequency response function, making the problem sensitive to small perturbations such as 
measurement errors or noise. In other words, the existence, the uniqueness, or the stability of the solution might be disrupted. To avoid divergent or inaccurate results, it is, therefore, necessary to exploit a regularization method. Regularization has been the hot topic in the context of inverse problems for almost 50 years, and, more interestingly, there is still a lot of research being conducted by mathematicians and engineering scientists to develop new and more accurate regularization techniques. Inverse problems are normally challenging, as there are uncertainties that usually get amplified through the inverse process and therefore need to be properly addressed [5]. The inverse problems are performed in the time domain, frequency domain, and even the time-frequency domain $[6,7]$.

This special issue mainly focuses on inverse problems in the context of system dynamics and vibration. Inverse dynamics, in particular, focusing on structural dynamics and/or inverse rigid body dynamics calculates the applied forces or internal forces and moments from measurements of structural vibrations and/or rigid body motions. The dynamic response can be measured using various types of contact and non-contact transducers including strain gauges, triangulation displacement sensors, laser Doppler vibrometers, accelerometers, and many other types of sensors [8].

As a widely used practical application of inverse problems in vibration engineering, impact force identification has attracted a great deal of attention [9-11]. Accidental external impact loading on structures makes them susceptible to different sorts of structural damage that reduces their load-carrying capabilities and may eventually give rise to catastrophic failure during service life. Identifying damage at the earliest possible stage by the determination of the impact location and magnitude can create a speedy structural health monitoring system. Identification of the impact loading on a structure is essential for structural integrity assessment and failure prediction. Additionally, structural condition assessment using moving sensors [12], time-varying load identification [13], moving load identification [14], bridge-weigh-in-motion systems [15], and human body and animal body inverse dynamics problems [16] are among other important applications of inverse problems in vibration engineering. Securing a more sustainable future by focusing on infrastructures' economic challenges can be achieved by the real-time monitoring of structures' health conditions through inverse algorithms.

The objective of this Special Issue was to create a forum of discussion for research scientists and engineers working in the area of inverse structural dynamics and inverse rigid body kinematics. We invited researchers to submit both original research and review articles. In total, 11 articles were accepted and published in this special issue. Herein, I would like to thank all the authors for their valuable time and effort contributing to the Special Issue.

Funding: This research received no external funding.

Institutional Review Board Statement: Not applicable.

Informed Consent Statement: Not applicable.

Conflicts of Interest: The author declares no conflict of interest.

\section{References}

1. Avdonin, S.; Edward, J. An Inverse Problem for Quantum Trees with Delta-Prime Vertex Conditions. Vibration 2020, 3, 448-463. [CrossRef]

2. Sengsri, P.; Ngamkhanong, C.; de Melo, A.L.O.; Kaewunruen, S. Experimental and numerical investigations into dynamic modal parameters of fiber-reinforced foamed urethane composite beams in railway switches and crossings. Vibration 2020, 3, 174-188. [CrossRef]

3. Sun, M.; Makki Alamdari, M.; Kalhori, H. Automated operational modal analysis of a cable-stayed bridge. J. Bridge Eng. 2017, 22, 05017012. [CrossRef]

4. Shooshtari, A.K.; Shemshadi, M.; Seraj, S. Effect of impeller diameter on dynamic response of a centrifugal pump rotor. Vibration 2021, 4, 117-129. [CrossRef]

5. Subber, W.; Ghosh, S.; Pandita, P.; Zhang, Y.; Wang, L. Data-Informed Decomposition for Localized Uncertainty Quantification of Dynamical Systems. Vibration 2021, 4, 49-63. [CrossRef] 
6. Senent, J.R.; García-Palacios, J.H.; Díaz, I.M. A Shake Table Frequency-Time Control Method Based on Inverse Model Identification and Servoactuator Feedback-Linearization. Vibration 2020, 3, 425-447. [CrossRef]

7. Yan, J.; Laflamme, S.; Singh, P.; Sadhu, A.; Dodson, J. A Comparison of Time-Frequency Methods for Real-Time Application to High-Rate Dynamic Systems. Vibration 2020, 3, 204-216. [CrossRef]

8. Kalhori, H.; Tashakori, S.; Halkon, B. Experimental Study on Impact Force Identification on a Multi-Storey Tower Structure Using Different Transducers. Vibration 2021, 4, 101-116. [CrossRef]

9. Kalhori, H.; Alamdari, M.M.; Li, B.; Halkon, B.; Hosseini, S.M.; Ye, L.; Li, Z. Concurrent Identification of Impact Location and Force Magnitude on a Composite Panel. Int. J. Struct. Stab. Dyn. 2020, 20, 2042004. [CrossRef]

10. Kalhori, H.; Alamdari, M.M.; Ye, L. Automated algorithm for impact force identification using cosine similarity searching. Measurement 2018, 122, 648-657. [CrossRef]

11. Kalhori, H.; Ye, L.; Mustapha, S. Inverse estimation of impact force on a composite panel using a single piezoelectric sensor. J. Intell. Mater. Syst. Struct. 2017, 28, 799-810. [CrossRef]

12. Do, N.T.; Gül, M.; Nafari, S.F. Continuous evaluation of track modulus from a moving railcar using ANN-based techniques. Vibration 2020, 3, 149-161. [CrossRef]

13. Gursoy, E.; Niebur, D. Harmonic load identification using complex independent component analysis. IEEE Trans. Power Deliv. 2008, 24, 285-292. [CrossRef]

14. Zhu, X.; Law, S. Practical aspects in moving load identification. J. Sound Vib. 2002, 258, 123-146. [CrossRef]

15. Kalhori, H.; Alamdari, M.M.; Zhu, X.; Samali, B.; Mustapha, S. Non-intrusive schemes for speed and axle identification in bridge-weigh-in-motion systems. Meas. Sci. Technol. 2017, 28, 025102. [CrossRef]

16. Hayati, H.; Eager, D.; Peham, C.; Qi, Y. Dynamic Behaviour of High Performance of Sand Surfaces Used in the Sports Industry. Vibration 2020, 3, 410-424. [CrossRef] 